\title{
Role of effective thermoregulation in premature neonates
}

\author{
This article was published in the following Dove Press journal: \\ Research and Reports in Neonatology \\ 9 September 2014 \\ Number of times this article has been viewed
}

\section{Robin B Knobel-Dail \\ School of Nursing and School of Medicine, Duke University, Durham, NC, USA}

Correspondence: Robin B Konbel-Dail School of Nursing and School of Medicine, Duke University, 307 Trent Drive, Durham, NC 277I0, USA

Tel +l 9196849295

Email robin.knobel@duke.edu
Abstract: Even though researchers have studied ways to reduce heat loss in premature infants for more than 100 years, hypothermia remains a widespread problem in this population, especially after birth and through the first weeks of life. This review focuses on current research findings that are being translated into practice to reduce heat loss after birth and during neonatal intensive care unit hospitalization. Recommendations for practice are given to minimize heat loss during care and promote thermal stability for very low birth weight infants. More research is needed to combine evidence-based interventions into thermoregulation bundles and to assess morbidity and mortality when such bundles are implemented. It is essential to continue to focus on thermal stability and eliminate hypothermia in the very low birth weight population.

Keywords: hypothermia, neonate, thermal stability, body temperature, stabilization

\section{Introduction}

Researchers have studied and clinicians have attempted to improve the thermal stability of infants for over 100 years. Silverman et al first linked infant hypothermia with increased mortality more than 60 years ago. ${ }^{1}$ Despite concentrated efforts in this area, hypothermia continues to be a major problem for premature infants, necessitating special care at birth and throughout the neonatal intensive care unit (NICU) hospitalization. Current guidelines are still debated and more research is needed to eliminate hypothermia and improve infant thermal stability in order to improve outcomes in these fragile infants.

\section{Mechanisms of heat loss}

An infant loses heat through its skin and respiratory tract to the environment through radiation, conduction, convection, and evaporation. Fat under the skin acts as an insulator to prevent heat loss; however, the more prematurely an infant is born, the less fat insulation there will be. It is important to understand the mechanisms of heat loss so that interventions can be aimed to block the transfer of heat from the infant to the environment.

\section{Radiation}

All body surfaces emit heat in the form of electromagnetic waves, ${ }^{2}$ which is called radiation. Body temperature will decrease or increase depending on the energy transferred through radiation, and the rate of heat loss is proportional to the temperature difference between the skin and the radiating surface. ${ }^{3}$ An infant may lose heat to a 
cold wall located nearby or gain heat from a over-bed heat source on a warming table through radiation.

\section{Conduction}

An infant can lose heat through conduction when their skin surface touches a colder object, such as a cold blanket. Conductive heat loss can occur through exposure to colder air, fluids, or solid surfaces. Heat will transfer from the warm molecules of the infant's skin to the colder molecules of the alternate surface as the molecules collide. Prewarming surfaces and fluids will minimize conductive heat losses while caring for a premature infant.

\section{Convection}

When heat is transferred from the skin to the environment through moving air or water, convective heat transfer occurs. Heat will be transferred from an infant's skin to the air when the skin is warmer than the air. The molecules rise into the air from the skin due to being less dense than colder molecules, then the heat molecules are swept away by convection through air or water. Convective heat loss is amplified in the delivery room when an infant is delivered into a cold room, then carried from the mother to a nearby warming table. As the infant is carried through the cold air, heat easily rises off the skin and is swept away.

\section{Evaporation}

Heat loss from evaporation occurs through the skin or respiratory tract when water is converted to a gas. The evaporative rate is proportional to the water vapor-pressure gradient between the skin and environment; there is a linear relationship between the ambient humidity and the evaporation rate, with higher evaporation rates at lower levels of humidity. ${ }^{4}$ Evaporation causes $0.6 \mathrm{kcal}$ of heat to be lost for every $1 \mathrm{~g}$ of water lost from the body. ${ }^{2}$ Hammerlaud et al found that evaporative heat loss is greatest right after birth ${ }^{5}$ therefore, interventions in the delivery room to reduce heat loss should be targeted towards reducing evaporative heat loss.

\section{Hypothermia at birth}

Much of the debate around hypothermia begins with a discussion related to the definition of normal body temperature in neonates. The American Academy of Pediatrics (AAP) defined the lower limits of normal temperature for an infant as $36.4^{\circ} \mathrm{C}$ in their 1988 perinatal guidelines. ${ }^{6}$ In an updated guideline, the AAP suggests an axillary temperature of $36.5^{\circ} \mathrm{C}$ in the delivery room and a range of $36.5^{\circ} \mathrm{C}-37.4^{\circ} \mathrm{C}$ prior to discharge. ${ }^{7}$ The World Health Organization (WHO) defines normal body temperature as $36.5^{\circ} \mathrm{C}-37.5^{\circ} \mathrm{C}$, with the degree of hypothermia stratified into three levels: mild hypothermia $\left(36^{\circ} \mathrm{C}-36.4^{\circ} \mathrm{C}\right.$, which should trigger cause for concern; moderate hypothermia $\left(32^{\circ} \mathrm{C}-35.9^{\circ} \mathrm{C}\right)$, which should prompt immediate rewarming of the infant; and severe hypothermia (temperature less than $32^{\circ} \mathrm{C}$ ), where the outlook for the infant is grim. ${ }^{8}$ From these guidelines, it is evident that clinicians should strive to keep infant body temperature above $36.5^{\circ} \mathrm{C}$ as a minimum safe level to prevent hypothermia.

Infants maintain a body temperature about $0.3^{\circ} \mathrm{C}-0.5^{\circ} \mathrm{C}$ higher than their mothers' temperature in utero. ${ }^{9}$ Once an infant is delivered at birth from the mother's uterus and the umbilical cord is clamped, non-shivering thermogenesis will be activated to allow for metabolic heat production in the brown adipose tissue. However, non-shivering thermogenesis is inefficient in infants less than about 32 weeks' gestational age due to developmental deficiencies, causing infants to lose more heat than they can generate and allowing for hypothermic body temperatures. ${ }^{10-12}$ When an infant is delivered into a cold delivery room, covered with amniotic fluid, evaporative and convective heat loss is certain. Body temperatures can fall to extremely low levels if auxiliary heat is not provided.

Evidence continues to link hypothermia after birth with neonatal morbidity and mortality. Laptook et al examined 5,277 infants born between 2002 and 2003 weighing 401-1,499 g. ${ }^{13}$ Hypothermia was prevalent in this group, with $14.3 \%$ of the infants having an admission temperature less than $35^{\circ} \mathrm{C}$ and $32.6 \%$ having a temperature between $35^{\circ} \mathrm{C}$ and $35.9^{\circ} \mathrm{C}$. These researchers found that admission temperature was inversely related to mortality, with a $28 \%$ increase in death for every $1^{\circ} \mathrm{C}$ decrease in temperature, and with lateonset sepsis, with an $11 \%$ increase in sepsis for every $1^{\circ} \mathrm{C}$ decrease in temperature. ${ }^{13}$ Miller et al conducted a study of 8,782 very low birth weight infants from 2006 to 2007 through the Californian Perinatal Quality Care Collaborative to examine admission temperatures, hypothermia, and outcomes. ${ }^{14}$ The mean ( \pm standard deviation) admission temperature was $36.3^{\circ} \mathrm{C} \pm 0.8^{\circ} \mathrm{C}$ across the cohort. Using the levels of hypothermia defined by the $\mathrm{WHO},{ }^{8}$ these researchers found $30.5 \%$ of the infants had mild hypothermia upon admission, $25.6 \%$ were moderately hypothermic, and $0.1 \%$ were severely hypothermic. Although mild hypothermia was not statistically significant with regard to any of the tested outcomes, moderate hypothermia was associated with higher odds of intraventricular hemorrhage (odds ratio 1.3, 95\% confidence interval [CI] 1.1-1.6) and death (odds ratio $1.5,95 \%$ CI 1.3-1.9). Severe hypothermia was seen in nine 
infants, with higher odds of death (odds ratio 5.6, 95\% CI 1.1-28.1). Most recently, researchers from the Brazilian Network on Neonatal Research conducted a study in 1,764 infants between 23 and 33 weeks' gestational age and found that hypothermia at neonatal admission increased the chance of early death by 1.64 -fold (95\% CI 1.03-2.61). ${ }^{15}$

From this evidence, despite many interventions implemented over the last 15 years to improve admission temperatures in premature infants, hypothermia upon admission still exists and is linked to worse outcomes. We must continue to find ways to combine thermal interventions to decrease heat loss in very low birth weight infants, usually less than 32-33 weeks' gestational age, while extending the studies to guard against heat loss in the first few days of life. Heat loss begins in the delivery room after an infant is delivered from the warmth of the intrauterine environment, usually into a drafty, cold delivery room. Interventions to prevent heat loss should begin at birth.

\section{Thermal stability in premature infants after birth}

McCall et al recently published an extensive review of interventions studied to prevent heat loss after birth in premature infants. ${ }^{16}$ After searching several electronic databases up to 2013, these researchers identified key interventions studied to reduce heat loss in the delivery room: increasing ambient temperature in the delivery room, using heated humidified gases, using exothermic or thermal mattresses, use of heat loss barriers such as head coverings or plastic body coverings, and applying skin-to-skin kangaroo care.

\section{Delivery room temperature}

According to AAP/American Congress of Obstetricians and Gynecologists (ACOG) ${ }^{7}$ standards, ambient air should be kept between $22^{\circ} \mathrm{C}$ and $26^{\circ} \mathrm{C}$ with a relative humidity of $30 \%-60 \%$ for infants outside of their incubator environment; however, the $\mathrm{WHO}^{8}$ and the International Liaison Committee on Resuscitation ${ }^{17} 2010$ guidelines recommend that air temperatures should be greater than $25^{\circ} \mathrm{C}-26^{\circ} \mathrm{C}$. According to the review by McCall et al, ${ }^{16}$ only two of the 22 studies they reviewed attempted to keep delivery room temperatures higher than $26^{\circ} \mathrm{C}$ when testing interventions to reduce heat loss at birth. When our team evaluated use of polyurethane bags to decrease heat loss in infants younger than 29 weeks' gestational age, we attempted to have clinicians increase delivery room temperature to $26^{\circ} \mathrm{C}$ prior to each delivery. ${ }^{18}$ This proved to be an impossible task to accomplish; therefore, we analyzed delivery room temperature as a covariate and found that although the plastic bags increased admission temperatures, a warmer delivery room increased the effect. Although this simple intervention has been found to work in increasing core body temperature in premature infants, ${ }^{19}$ clinicians are not consistent in increasing delivery room temperature. If effort is made to adjust the delivery room ambient air temperature prior to each delivery, along with implementing other thermal stability interventions, it is possible to completely eliminate the incidence of hypothermia as one group did in a quality improvement project over several years. $^{20}$

\section{Heated humidified gases}

Recommendations in this area are lacking, and standard care has suggested resuscitating with dry room air gas or dry oxygenated gas. Heat can be loss in two ways through this method, ie, through evaporation due to use of air without humidity and through conduction due to contact of cold dry gas with the warm gases of the internal respiratory tract. The recently published 2013 European Consensus guidelines suggest that using heated humidified air in infants with respiratory distress syndrome may improve thermal stability. ${ }^{21}$ In the studies reviewed by $\mathrm{McCall}$ et al, ${ }^{16}$ using heated humidified air resulted in a significant decrease in hypothermia; however, the researchers cautioned that the safety aspects of this intervention have not been studied. A recent study reported by the Brazilian Network on Neonatal Research showed that respiratory support with cold air in the delivery room was associated with hypothermia upon neonatal admission (odds ratio $1.40,95 \% \mathrm{CI} 1.03-1.88$ ) and during transport to the unit (odds ratio1.51, 95\% CI 1.08-2.13). ${ }^{15}$ More research is needed to confirm this intervention as a strong contributor to thermal stability without increased risk to the infant.

\section{Thermal mattresses}

Traditionally, thermal or exothermic mattresses have been used for transport of premature infants in cold environments. However, more recently, we have been using exothermic mattresses or thermal mattresses in the NICU to increase or substitute for heat inside an incubator. McCall et al found evidence in their search of two randomized controlled trials (RCT)s and one crossover trial showing that heated mattresses were just as effective in warming premature infants as incubators. ${ }^{16}$ This group also found studies with evidence that using warming blankets after birth on infants younger than 32 weeks' gestational age could improve body temperature compared with routine care. For a complete review of this intervention, the reader is referred to the paper by 
McCall et al. ${ }^{16}$ They also caution that combining thermal mattresses with other thermal stability interventions may result in hyperthermia and should be used with care. Current guidelines warn that combining plastic sheeting with thermal mattresses could result in hyperthermia. ${ }^{21}$

\section{Plastic coverings}

Saran wrap or plastic sheets have been used to improve thermal stability of infants since the $1970 \mathrm{~s} .{ }^{22}$ This barrier will reduce evaporative heat $\operatorname{loss}^{5}$ and allow radiative heat to pass through the plastic barrier to increase an infant's temperature. When polyurethane or polyethylene wrap is used after birth, it is applied while the infant is still wet with amniotic fluid to keep the infant in a warm, moist coating under the plastic. ${ }^{18}$ Many researchers conducted studies using this intervention in the late 1990 s to early 2000s that have been thoroughly reviewed in a Cochrane database review. ${ }^{23}$ In a meta-analysis by the group conducting the Cochrane review using data from four RCTs to examine admission temperature in infants with the plastic bag/wrap intervention compared with standard care, it was found that the incidence of hypothermia (temperatures less than $36.4^{\circ} \mathrm{C}$ ) was significantly reduced when the intervention was used. By 2006, the fifth edition of the Neonatal Resuscitation Program textbook began to recommend some type of plastic covering/wrap around infants born premature prior to 28 weeks' gestational age. ${ }^{24}$

The use of plastic barriers to prevent heat loss after birth is now being studied for use in term infants in low-resource settings. Belsches et al conducted a parallel-group RCT at a teaching hospital in Zambia to test the use of plastic bags to prevent heat loss in infants $\geq 37$ weeks gestational age and $\geq 2,500 \mathrm{~g}$ within 10 minutes of birth. ${ }^{25}$ The primary outcome was hypothermia (axillary temperature $<36.5^{\circ} \mathrm{C}$ ) at one hour of age. The group found a lower incidence of hypothermia ( $60 \%$ versus $73 \%$, risk ratio 0.76 , CI $0.60-0.96$, $P=0.26)$ in the infants placed in bags when compared with infants receiving standard care. This is an extremely important finding, in that hypothermia is an even more widespread problem in low-resource countries and this intervention is an easy, low-cost one. It is important to note that the hypothermia rate of $60 \%$ in that study is still very high and more studies need to be done to combine other solutions to help reduce hypothermia in low-resource settings.

Researchers are also looking at the use of plastic head coverings to decrease heat loss after birth. Trevisanuto et al conducted an RCT with infants $<29$ weeks gestational age, assigning the infants to three groups: one using polyethylene caps on the head after the body was dried, another group placed in polyethylene bags while wet and head dried but left uncovered, and a third group of infants who were dried routinely and placed on warm towels. ${ }^{26}$ The infants in the polyethylene cap group had less hypothermia (axillary temperature $<36.4^{\circ} \mathrm{C}$ ) than those in the bag group or routine care group; however, examining the group means, there was still $43 \%, 62 \%$, and $90 \%$ of infants with hypothermic temperatures upon admission to the NICU in the three groups, respectively, with all three group means $>36.2^{\circ} \mathrm{C}$.

Doglioni et al conducted an RCT in 100 premature infants to examine use of wrapping the total body (head and torso) in polyethylene covering versus wrapping the body only. ${ }^{27}$ The results showed that thermal stability was similar in both groups. The researchers found an incidence of moderate hypothermia in $12 \%$ of the total body group and $20 \%$ of the control group $(P=0.41)$. Three infants had body temperatures $>37.5^{\circ} \mathrm{C}$ and one infant had an axillary temperature of $>38^{\circ} \mathrm{C}$. More research is needed to investigate combining such interventions to improve thermal stability.

\section{Skin-to-skin care after birth}

Placing an infant on the mother's chest after birth has long been the standard of care for term infants to help with maternal-infant bonding. Skin-to-skin care, or kangaroo care, has become an established method to prevent heat loss, even in premature infants. ${ }^{28}$ International standards recommend skinto-skin care between the mother and infant within 24 hours of birth. ${ }^{23}$ Mori et al conducted a meta-analysis of 23 studies evaluating skin-to-skin care from 1989 to 2005, finding skinto-skin care facilitates an increase in body temperature..$^{29,30}$ A Cochrane review with 34 RCTs including preterm and term infant-mother pairs investigating skin-to-skin care begun within 24 hours of birth, found only three studies reporting body temperatures after birth and with inconclusive results. The review conducted by $\mathrm{McCall}$ et $\mathrm{al}^{16}$ of skin-to-skin care just after birth also found mixed study results, with no clear recommendation that skin-to-skin care is a good thermal intervention in premature infants just after birth.

\section{Combining interventions}

It is clear that premature infants continue to have hypothermia after birth, despite our best efforts. More studies are needed that combine thermal interventions and evaluate outcomes, including morbidity and mortality. Recently, a few quality improvement projects have been published where clinicians have attempted to bundle thermal interventions and evaluate body temperature in premature infants after birth. Manani et al report that they eliminated hypothermia in a cohort of 
infants born in 2011 in San Jose, CA, USA, by using their thermal support bundle. ${ }^{20}$ Targeting an admission temperature between $36^{\circ} \mathrm{C}$ and $37^{\circ} \mathrm{C}$, the clinicians investigated the source of their thermal stability problems through root cause analysis, then implemented thermal guidelines incorporating use of a prewarmed resuscitation bed, polyethylene occlusive wrap, chemically activated warming mattress, warming lights during initial admission, newborn hat, and warmed blankets. They also aimed to increase delivery room temperature $\geq 25^{\circ} \mathrm{C}$. Their protocol included signage to remind clinicians about the importance of thermal stability and education to the staff as an update. They monitored for the incidence of hypothermia between 2006 and 2011. The team reported an increase in the incidence of hyperthermia as admission temperatures improved. These clinicians adjusted their protocol to remove the plastic wrap once the infant's temperature was $>36.5^{\circ} \mathrm{C}$. Using these steps, this group reduced the incidence of hypothermia to $0 \%$ in 2009 and 2011 .

Another group from Albany, NY, USA, and a member of the Vermont Oxford Network, implemented a thermoregulation bundle as part of a quality improvement project over 5 years to target admission temperatures within a range of $36^{\circ} \mathrm{C}-38^{\circ} \mathrm{C}$ in $\geq 90 \%$ of their very low birth weight infants. ${ }^{31}$ Because the group had no way of increasing temperature in the delivery room, they kept their stabilization room doors closed to promote higher ambient temperatures from the heat radiating from overhead warmers. The thermoregulation bundle also included wrapping the head and torso of each infant in plastic sheeting, using warming blankets, and stabilization on warmers. They analyzed 641 infant temperatures and found the incidence of hypothermia to be less than $10 \%$ for more than 2 years. Mean body temperature increased from $36.2^{\circ} \mathrm{C} \pm 0.9^{\circ} \mathrm{C}$ prior to implementing the bundle to $36.8^{\circ} \mathrm{C} \pm 0.5^{\circ} \mathrm{C}$ afterwards. The incidence of hyperthermia remained at about $2 \%$. Other centers have implemented similar thermoregulation bundles with similar results. ${ }^{32,33}$

\section{Recommendations for practice}

The trend towards implementing quality improvement projects using the evidence gained over the last 30 years seems to offer the best solution for reducing hypothermia after birth in premature infants. Interventions within the thermal stability bundles can be readjusted with ongoing data collection and analyses. If specific interventions are aimed towards reducing conductive, radiative, evaporative, and convective heat losses, then body temperatures should improve. It is also important to conduct ongoing education and post signage as reminders to be vigilant in pursuing thermal stability. Thermoregulation bundles may include: increasing delivery room/stabilization room temperature to $25^{\circ} \mathrm{C}-26^{\circ} \mathrm{C}$, covering the body and head of infants less than 28 weeks' gestational age with polyethylene or polyurethane sheeting while still wet, using a thermal or exothermic warming mattress either in the delivery room or during transport, placing infants on prewarmed surfaces, and exposing them only to heated ambient air. Clinicians may also want to investigate or consider skin-to-skin care briefly after delivery and the use of heated, humidified air/oxygen if respiratory resuscitation is needed.

\section{Special considerations for infant transport}

It is important to pay attention to the body temperature of a premature and/or sick infant before and during transport between facilities. Goldsmit et al examined 160 infant transport records and found that $46 \%$ of the infants suffered from hypothermia. ${ }^{34}$ Heat should be provided during stabilization care at the referring hospital to ensure adequate body temperature prior to starting transport. Infants should be stabilized on warming tables with auxiliary heat if necessary. Infant body temperature should be maintained during transport with a transport incubator on servo control. Using a heated gel mattress such as a Transwarmer ${ }^{\circledR}$ infant transport mattress (Cooper Surgical, Trumbull, CT, USA) will also reduce hypothermia during transport. ${ }^{35}$ Many of the interventions described previously to reduce the heat loss after birth, such as prewarmed surfaces, auxiliary heat, and warmed respiratory gases, can be applied during transport. When environmental temperatures are extreme, attempt to warm the inside of the ambulance or aircraft to the recommended environmental room temperature of at least $25^{\circ} \mathrm{C}-26^{\circ} \mathrm{C} .{ }^{8}$ Because the long-term effects of hyperthermia in a premature infant have not been studied, it is important to judge how warm the infant's environment is during transport and monitor body temperature frequently during the journey. If the environment is too warm for transport personnel, it is likely that an infant may overheat with interventions in place to prevent hypothermia.

\section{Hypothermia during NICU hospitalization}

Because premature infants are unable to maintain body temperature without an additional heat source in their environment, it is necessary to control body temperature to minimize heat loss and metabolic expenditures throughout the NICU hospitalization. Maintaining a normal body temperature will allow for good growth and development, and decrease the 
incidence of morbid outcomes. Before we can examine how to reduce heat loss, there must be a discussion about normal body temperature for premature infants.

\section{Normal body temperature}

Neonatal texts suggest a range of temperature by site for premature infants: rectal temperature should be $36.5^{\circ} \mathrm{C}-37.5^{\circ} \mathrm{C}$, skin temperature should be $36.2^{\circ} \mathrm{C}-37.2^{\circ} \mathrm{C}$, and axillary temperature should be $36.5^{\circ} \mathrm{C}-37.3^{\circ} \mathrm{C} .{ }^{36}$ The most recent update from the AAP/ACOG suggests an axillary temperature of $36.5^{\circ} \mathrm{C}-37.4^{\circ} \mathrm{C}$ prior to discharge for an infant in an open crib. ${ }^{7}$ We examined ten infants weighing less than $1,000 \mathrm{~g}$, over their first 12 hours after birth, to determine the abdominal skin temperature associated with the most stable hear rate trends (inner 50th percentile). We determined that clinicians should target a temperature of $36.8^{\circ} \mathrm{C}-36.9^{\circ}$ in infants earlier than 28-29 weeks' gestational age to keep infants' heart rates stable and minimize heat loss. A minimum safe temperature for all infants should be $36.5^{\circ} \mathrm{C} .{ }^{37} \mathrm{We}$ determined that clinicians should target a temperature of $36.8^{\circ} \mathrm{C}-36.9^{\circ} \mathrm{C}$ in infants younger than 28-29 weeks' gestational age to minimize heat loss, and a minimum safe temperature for all infants should be $36.5^{\circ} \mathrm{C}$. There are several areas to contemplate when planning strategies for good thermal care to maintain a neutral thermal environment for premature infants. We must consider the environment surrounding each infant, strategies to ensure thermal stability during care, and transitioning infants from NICU care through to discharge home.

\section{Environmental temperature}

One important factor to regard in preventing heat loss is the environmental temperature and relative humidity inside the NICU because when an infant is removed from their incubator for any reason, the infant is exposed to the ambient air outside the incubator. AAP/ACOG standards suggest keeping the ambient room temperature between $22^{\circ} \mathrm{C}$ and $26^{\circ} \mathrm{C}$ with a relative humidity level of $30 \%-60 \%{ }^{7}$ Because the body temperature of premature infants in one study was found to decrease by up to $1.08^{\circ} \mathrm{C}$ per hour for some care procedures due to the type of procedure, length of procedure, and opening of the incubator, ${ }^{38}$ it is important to minimize exposure to cold ambient air and use auxiliary heat for long procedures. Thomas et al found that there was a seasonal interaction with NICU room temperature, with ambient room temperatures differing as much as $2^{\circ} \mathrm{F}$ across seasons. ${ }^{39}$ These researchers recommend checking the room temperature and humidity levels during each season to assess for changes out of the recommended temperature/humidity ranges.

\section{Incubator environments}

Incubators have been used to house premature infants since the 1800s when Tarnier invented the first enclosed, heated incubator. ${ }^{40}$ Incubators have long been the standard of care to prevent heat loss and to surround an infant with a warm, moist environment. These housing units provide good visibility to the infant and a servo control device with a feedback system. A control temperature can be set for an infant's skin temperature, and the device, usually referred to as incubator servo control, will increase or decrease heat to keep the infant at that control temperature. An incubator will also have a fan to circulate the warm air and a vessel or way to add water to produce a humid environment. Unfortunately, incubators also serve as a barrier between infants and their families, most importantly their mothers and fathers, which decreases the bonding experience and lessens human touch. Another disadvantage is that an incubator is potentially hazardous to the infant due to the use of electricity and heating elements as well as an increased infection risk from the warm moist environment.

The warm moist environment may contribute to an infection risk to the infant. De Goffau et al examined Caleo incubators for hot and cold spots in a group of infants housed in incubators kept at $\geq 34^{\circ} \mathrm{C}$ and $\geq 60 \%$ humidity versus a group of infants housed in incubators kept at $<34^{\circ} \mathrm{C}$ and $<60 \%$ humidity. ${ }^{41}$ The researchers found prolific Staphylococcal bacteria in incubators with cold spots where the humidity level was above $60 \%$. Cold spots were found in the incubators of the infants housed at lower temperatures and humidity; however, the bacteria were not present at a statistically significant higher level. This study suggests that it is important to wean the humidity level down below $60 \%$ as soon as possible to prevent bacterial growth in warm incubators.

Incubators should have double walls if possible, because this will decrease the amount of heat loss, decrease the need for heat production, and reduce oxygen consumption, according to a 2009 update Cochrane review examining single-wall compared with double-wall incubators. ${ }^{42}$ The authors of this Cochrane review did caution that no long-term benefits were seen in infant outcomes, mortality, or length of stay when double-wall incubators were used; however, the short-term benefits warrant their use if they are financially available.

\section{Radiant warmers}

Studies comparing radiant warmers against incubators to determine the best method of care for premature infants were done in the 1970s and 1980s. The Cochrane review completed in 2003, with no recent updates, concluded that radiant warmers cause significant increases in insensible water loss and 
increases in oxygen consumption, which is a disadvantage when caring for premature infants. ${ }^{43}$ Radiant warmers are still a good choice when it is necessary to reach the infant easily for a short period of time, such as stabilization after birth and for surgical procedures.

\section{Humidity}

Premature infants with high evaporative water losses and thin skin require care in humid environments. Researchers have examined the use of humidity in the care of infants since the $1930 \mathrm{~s}^{44}$ The use of humidity has wide practice variation, as confirmed through multiple survey studies. ${ }^{45,46}$ NICU clinicians add humidity to the incubator anywhere from the time of infant admission to 72 hours of age, and it is used for up to 28 days of life. The amount of humidity varies between $45 \%$ and $100 \%$. Standards do not exist to guide protocols for use of humidity. Kim et al conducted a retrospective review comparing 87 infants housed in incubators without humidity versus 95 infants housed in incubators with high humidity (70\%-80\% week 1, 50\%-60\% week 2 and beyond). ${ }^{47}$ They found body temperature to be similar in both groups; however, infants cared for in humid environments had less fluid intake, urine output, and insensible water loss. There was also less maximum weight loss and a lower incidence of hypernatremia during the first week in the high humidity group. These researchers did not find an increased infection rate in the high humidity group. One problem with increased humidity in the care of premature infants is an apparent delay in maturation of the skin barrier. Agren et al found transepidermal water losses to be higher, with subsequent decreases in those losses being delayed when humidity was $75 \%$ compared with $50 \%$. ${ }^{48}$

\section{Skin-to-skin care during NICU hospitalization}

Just as skin-to-skin care is advantageous after birth in promoting maternal bonding while keeping an infant warm, this type of care is an effective way to maintain body temperature during the NICU stay, while allowing the parents to become close to their infant. ${ }^{28}$ In Denmark, Maastrup et al evaluated skin-to-skin care in 22 stable premature infants with a mean gestational age of 25 weeks and a mean birth weight of $702 \mathrm{~g}$, and found evidence of an increase in body temperature with skin-to-skin care compared with body temperature in infants prior to skin-to-skin care (weighted mean difference $0.22^{\circ} \mathrm{C}$, $P<0.01) .{ }^{49}$ In this study, skin-to-skin care took place in a NICU where the ambient room temperature was $25^{\circ} \mathrm{C}-27^{\circ} \mathrm{C}$; mean skin temperature of the infants receiving skin-toskin care was $37^{\circ} \mathrm{C} \pm 0.33^{\circ} \mathrm{C}$. This intervention can also be particularly valuable in low-resource settings and third world countries where a large supply of incubators does not exist.

\section{Weaning from thermally controlled care to open cribs}

There are very few standards based on scientific evidence to guide clinicians on the manner, timing, and method of moving an infant from a heated incubator to an open crib or cot. Survey research verifies that practice varies widely for this procedure. New et al described practices in Australian and New Zealand from a survey of 78 nurse leaders from 109 NICUs. ${ }^{50}$ Standards in these NICUs required infants to be transferred from an incubator to an open crib anywhere from $1,200 \mathrm{~g}$ to $1,800 \mathrm{~g}$. The majority of the respondents said an infant would need to be stable at $29^{\circ} \mathrm{C}$ before weaning from an incubator, but $26 \%$ of the respondents specified an environmental temperature less than $29^{\circ} \mathrm{C}$ as a criterion before weaning infants. These NICUs employed different strategies to help wean an infant from an incubator to an open crib, with $83 \%$ using incubator air control first, 85\% using a thermal challenge, $59 \%$ placing infants in clothing, $10 \%$ of the NICUs first placing an infant in a single wall incubator and $28 \%$ using some sort of external heating device such as a thermal mattress. Less than $50 \%$ of the NICU respondents surveyed actually had written guidelines for the procedure.

The Association of Women's Health, Obstetrics and Neonatal Nursing conducted a utilization project in the 1990s implementing a specific weaning protocol for very low birth weight premature infants from an incubator to an open crib in ten NICUs. ${ }^{51}$ Infants were transferred at an approximate weight of 1,500 $\mathrm{g}$ after 5 consistent days of weight gain and when medically stable. This project showed that a standardized weaning protocol could be implemented, and infants could be transferred successfully to an open crib using the protocol. Even though this project was conducted in the early 1990 s, there still appears to be a wide variation in practice concerning the steps implementing successful transfer of infants from an incubator to an open crib.

Three studies have been reviewed which support the criterion of weaning infants from an incubator to an open crib at 1,600 g. ${ }^{52-54}$ A Cochrane review also confirms that infants can be safely transferred at $1,600 \mathrm{~g} .{ }^{55}$ Schneiderman et al concluded that for every incremental $100 \mathrm{~g}$ increase of weight in infants at the time of transfer to an open crib there was an associated increase in time of 0.8 days until the infant reached full enteral feeds and an increased length of stay of 0.9 days. ${ }^{52}$ These researchers recommended transferring infants once they reach a weight of $1,500 \mathrm{~g}$. Zecca et al found 
that transferring infants at weights less than $1,600 \mathrm{~g}$ resulted in a significant decrease in length of stay (23.5 versus 33 days, $P=0.0002$ ) compared with transferring infants at $1,600 \mathrm{~g}$ or more. ${ }^{53}$ Lastly, New et al found that infants transferred at $1,800 \mathrm{~g}$ had more temperatures less than $36.4^{\circ} \mathrm{C}$ recorded than infants transferred at 1,600 $\mathrm{g}$ in the first 72 hours after transfer. Infants in the 1,600 g group had a larger average daily weight gain than those in the heavier group $(17.07 \pm 4.5 \mathrm{~g} / \mathrm{kg} / \mathrm{day}$ versus $13.97 \pm 4.7 \mathrm{~g} / \mathrm{kg} /$ day, $P<0.001)$.

\section{Recommendations for practice}

It is important that we pay attention to the thermal stability of each infant from all aspects of care during NICU hospitalization. We have seen that the NICU ambient temperature and relative humidity need to be controlled, with special attention paid to any changes that may occur with seasonal effects. Rooms should be kept at $22^{\circ} \mathrm{C}-26^{\circ} \mathrm{C}$ with a relative humidity of $30 \%-60 \%$. Infants should be kept in double-wall incubators, if resources allow, and their body temperature controlled at an incubator servo control skin temperature of a minimum of $36.5^{\circ} \mathrm{C}$, increasing to $36.8^{\circ} \mathrm{C}-36.9^{\circ} \mathrm{C}$ for extremely premature infants. We should monitor inside incubator temperature and attempt to minimize the amount of time we spend in incubators for care, as well as minimize the amount of time an infant spends outside their incubator. The relative humidity levels need to be standardized and weaned from $>60 \%$ as soon as the infant tolerates the decrease. When an infant has to be outside the incubator for a procedure or care, add auxiliary heat by way of warming lights and/or thermal mattresses to minimize heat loss. Skin-to-skin care is an excellent way to provide thermal stability to an infant, while increasing bonding and human touch time with the parents. Consider weaning infants from an incubator to an open crib at 1,500-1,600 $\mathrm{g}$ instead of $1,800 \mathrm{~g}$. All thermal guidelines should be evidence-based and standardized to decrease practice variation and provide optimal outcomes for all premature infants. This area of research is continually being updated and we must be vigilant in keeping our standards current.

\section{Conclusion}

Researchers have focused on improving the science of thermal stability in premature infants for over 100 years; however, hypothermia continues to be a problem that contributes to increased morbidity and mortality in this population. More research is needed to evaluate combining evidence-based interventions to eliminate the incidence of hypothermia from birth onwards. New ways of following continuous temperature in extremely premature infants are needed so that nurses are aware of cold body temperatures in real time, from the delivery room through stabilization. Once an infant is stabilized, we must ensure continued thermal stability to promote early discharge home. The WHO, AAP, and ACOG have recognized this continued problem and are behind ongoing efforts to find solutions to eliminate hypothermia in premature infants.

\section{Disclosure}

RBKD has received consultation payment from the Joint Commission and Mt Sinai Collaboration to Advance Pediatric Quality Measures Project 2012-2013 and guest editor payment from New and Infant Nursing Reviews. Funding for a study investigating body temperature in premature infants during stabilization in which Knobel-Dail is principal investigator (September 1, 2014-August 31, 2016) is being provided by Philips Healthcare. The author has no other conflicts of interest in this work.

\section{References}

1. Silverman W, Fertig J, Berger A. The influence of the thermal environment upon the survival of newly born premature infants. Pediatrics. 1958;22:876-886.

2. Hall JE. Guyton and Hall Textbook of Medical Physiology. 12th ed. Philadelphia, PA, USA: Saunders Elsevier; 2011.

3. Adams AK, Nelson RA, Bell EF, Egoavil CA. Use of infrared thermographic calorimetry to determine energy expenditure in preterm infants. Am J Clin Nutr. 2000;71:969-977.

4. Sedin G, Hammarlund K, Nilsson GE, Oberg PA, Stromberg B. Water transport through the skin of newborn infants. Ups J Med Sci. 1981;86: $27-31$.

5. Hammarlund K, Nilsson GE, Oberg PA, Sedin G. Transepidermal water loss in newborn infants. V. Evaporation from the skin and heat exchange during the first hours of life. Acta Paediatr Scand. 1980;69:385-392.

6. American Academy of Pediatrics and College of Obstetrics and Gynecologists. Guidelines for Perinatal Care. 2nd ed. Elk Grove, IL, USA: American Academy of Pediatrics; 1988.

7. American Academy of Pediatrics and College of Obstetrics and Gynecologists. Guidelines for Perinatal Care. Elk Grove Village, IL: American Academy of Pediatrics; 2012.

8. World Health Organization. Protection of the Newborn: A Practical Guide. Geneva, Switzerland: World Health Organization; 1997. Available from: http://whqlibdoc.who.int/hq/1997/WHO_RHT_ MSM_97.2.pdf. Accessed August 5, 2014.

9. Power GG, Schroder H, Gilbert RD. Measurement of fetal heat production using differential calorimetry. J Appl Physiol. 1984;57:917-922.

10. Houstek J, Vizek K, Pavelka S, et al. Type II iodothyronine 5'-deiodinase and uncoupling protein in brown adipose tissue of human newborns. J Clin Endocrinol Metab. 1993;77:382-387.

11. Knobel RB, Holditch-Davis D, Schwartz T, Wimmer JE. Extremely low birth weight preterm infants lack vasomotor response in relationship to cold body temperatures at birth. $J$ Perinatol. 2009;29:814-821.

12. Knobel RB. Fetal and neonatal physiology. Newborn Infant Nurs Rev. 2014; 14:45-49.

13. Laptook A, Salhab W, Bhaskar B, Network NR. Admission temperature of low birth weight infants: predictors and associated morbidities. Pediatrics. 2007;119:e643-e649. 
14. Miller SS, Lee HC, Gould JB. Hypothermia in very low birth weight infants: distribution, risk facors and outcomes. J Perinatol. 2011;31: S49-S56.

15. de Almeida MF, Guinsburg R, Snacho GA, et al. Hypothermia and early neonatal mortality in preterm infants. J Pediatr. 2014;164:271-275.

16. McCall E, Alderdice F, Halliday H, Johnston L, Vohra S. Challenges of minimizing heat loss at birth: a narrative overview of evidence-based thermal care interventions. Newborn Infant Nurs Rev. 2014;14: 56-63.

17. Richmond S, Wyllie J. Resuscitation council guidelines for resuscitation 2010. Section 7. Resuscitation of babies at birth. Resuscitation. 2010;81:1389-1399.

18. Knobel RB, Vohra S, Lehmann CU. Heat loss prevention in the delivery room for preterm infants: a national survey of newborn intensive care units. J Perinatol. 2005;25:514-518.

19. Jia YS, Lin ZI, Green R, Lin J. Effect of delivery room temperature on the admission temperature of premature infants: a randozimed controlled trial. J Perinatol. 2013;33:264-267.

20. Manani M, Jegatheesan P, DeSandre G, Song D, Showalter L, Govindaswami B. Elimination of admission hypothermia in preterm very low birth weight infants by standardization of delivery room managment. Perm J. 2013;17:8-13.

21. Sweet DG, Carnielli V, Greisen G, et al. European consensus guidelines on the management of neonatal respiratory distress syndrome in preterm infants - 2013 update. Neonatology. 2013;103:353-368.

22. Besch NJ, Perlstein PH, Edwards NK, Keenan WJ, Sutherland JM. The transparent baby bag. N Engl J Med. 1971;284:121-124.

23. McCall E, Alderdice F, Halliday HL, Jenkins JG, Vohra S. Interventions to prevent hypothermia at birth in preterm and/or low birthweight infants. Cochrane Database Syst Rev. 2010;3:CD004210.

24. American Academy of Pediatrics, American Heart Association. Neonatal Resuscitation. 5th ed. Elk Grove Village, IL, USA: American Academy of Pediatrics; 2006.

25. Belsches TC, Tilly AE, Miller TR, et al. Randomized trial of plastic bags to prevent term neonatal hypothermia in a resource-poor setting. Pediatrics. 2013;132:e656-661.

26. Trevisanuto D, Doglioni N, Cavallin F, Parotto M, Micaglio M, Zanardo V. Heat loss prevention in very preterm infants in delivery rooms: A prospective, randomized, controlled trial of polyethylene caps. J Pediatr. 2010;156:914-917.

27. Doglioni N, Cavallin F, Mardegan V, et al. Total body polyethylene wraps for preventing hypothermia in preterm infants: a randomized trial. J Pediatr. 2014;165:261-266. e1.

28. Bauer K, Uhrig C, Pasel K, Wieland C, Versmold HT. Body temperatures and oxygen consumption during skin-to-skin (kangaroo) care in stable preterm infants weighing less than 1500 grams. J Pediatr. 1997;130:240-244.

29. Mori R, Khanna R, Pledge D, Nakayama T. Meta-analysis of physiological effects of skin-to-skin contact for newborns and mothers. Pediatr Int. 2010;52:161-170.

30. Knobel RB. Thermal stability of the premature infant in neonatal intensive care. Newborn Infant Nurs Rev. 2014;14:72-76.

31. Pinheiro JMB, Furdon SA, Boynton S, Dugan R, Reu-Donlon C, Jenson $\mathrm{S}$. Decreasing hypothermia during delivery room stabilization of preterm neonates. Pediatrics. 2014;133:e218-e226.

32. Bobby PD, Cabral J, Cianella J, Matias S, Kelley E, Bowman D. Reducing the incidence of hypothermia in preterm neonates. Obstet Gynecol. 2012;123:139S.

33. Russo A, McCready M, Torres L, et al. Reducing hypothermia in preterm infants following delivery. Pediatrics. 2014;133:e1055-e1062.

34. Goldsmit G, Rabasa C, Rodriquez S, et al. Risk factors associated to clinical deterioration during the transport of sick newborn infants. Arch Argent Pediatr. 2012;110:304-309.

35. Almedia PG, Chandley J, Davis J, Harrigan RC. Use of the heated get mattress and its impact on admission temperature of very low birthweight infants. Adv Neonatal Care. 2009;9:34-39.
36. Rutter N. Temperature control and its disorders. In: Rennie JM, editor. Robertson's Textbook of Neonatology. 4th ed. London, UK: Churchill Livingstone; 2005.

37. Knobel RB, Holditch-Davis D, Schwartz T. Optimal body temperature in extremely low birth weight infants using heart rate and temperature as indicators. J Obstet Gynecol Neonatal Nurs. 2010;39:3-14.

38. Deguines C, Degrugilliers L, Ghyselen L, Chardon K, Bach V, Tourneux P. Impact of nursing care on temperature environment in preterm newborns nursed in closed convective incubators. Acta Paediatr. 2013;102: e96-e101.

39. Thomas K, Magbalot A, Shinabarger K, et al. Seasonal mapping of NICU temperature. Adv Neonatal Care. 2010;10:S2-S6.

40. Antonucci R, Porcella A, Fanos V. The infant incubator in the neonatal intensive care unit: unresolved issues and future developments. J Perinat Med. 2009;37:587-598.

41. de Goffau MC, Bergman KA, de Vries HJ, et al. Cold spots in neonatal incubators are hot spots for microbial contamination. Appl Environ Microbiol. 2011;77:8568-8572.

42. Laroia N, Phelps D, Roy J. Double wall versus single wall incubator for reducing heat loss in very low birth weight infants in incubators (2009). Cochrane Database Syst. 2007;2:CD004215.

43. Flenady V, Woodgate PG. Radiant warmers versus incubators for regulating body temperature in newborn infants. Cochrane Database Syst. 2003;4:CD000435.

44. Blackfan KD, Yaglou CP. The premature infant: a study of the effects of atmospheric condtions on growth and on development. Am J Dis Child. 1933;46:1175-1236.

45. Sinclair L, Crisp J, Sinn J. Variability in incubator humidity practices in the management of preterm infants. J Paediatr Child Health. 2009;45: 535-540.

46. Deguines C, Decima P, Pelletier A, Degrugilliers L, Ghyselen L, Tourneux P. Variations in incubator temperature and humidity managment: a survey of current practice. Acta Paediatr Scand. 2012;101: $230-235$.

47. Kim SM, Lee EY, Chen J, Ringer SA. Improved care and growth outcomes by using hybrid humidified incubators in very preterm infants. Pediatrics. 2010;125:e137-e145.

48. Agren J, Sjors G, Sedin G. Ambient humidity influences the rate of skin barrier maturation in extremely preterm infants. $J$ Pediatr. 2006;148:613-617.

49. Maastrup R, Greisen G. Extremely preterm infants tolerate skin-toskin contact during the first weeks of life. Acta Paediatr. 2010;99: 1145-1149.

50. New K, Bogossian F, East C, Davies MW. Practice variation in the transfer of premature infants from incubators to open cots in Australian and New Zealand neonatal nurses: results of an electronic survey. Int J Nurs Stud. 2009;47:678-687.

51. Medoff-Cooper B. Transition of the preterm infant to an open crib. J Obstet Gynecol Neonatal Nurs. 1994;23:329-335.

52. Schneiderman R, Kirkby S, Turenne W, Greenspan J. Incubator weaning in preterm infants and associated practice variation. J Perinatol. 2009;29:570-574.

53. Zecca E, Corsello M, Priolo F, Tiberi E, Barone G, Romagnoli C. Early warning from incubator and early discharge of preterm infants: randomized clinical trial. Pediatrics. 2010;126:e651-e656.

54. New K, Flint A, Bogossian F, East C, Davies MW. Transferring preterm infants from incubators to open cots at $1600 \mathrm{~g}$ : a multicentre randomised controlled trial. Arch Dis Child Fetal Neonatal Ed. 2012;97: F88-F92.

55. New K, Flenady V, Davies MW. Transfer of preterm infants from incubator to open cot at lower versus higher body weight. Cochrane Database Syst Rev. 2011;9:CD004214. 


\section{Publish your work in this journal}

Research and Reports in Neonatology is an international, peer-reviewed, open access journal publishing original research, reports, editorials, reviews and commentaries on neonatal health. The manuscript management system is completely online and includes a very quick and fair

peer-review system. Visit http://www.dovepress.com/testimonials.php to read real quotes from published authors. 